\title{
Ferrocene Containing Copolymers with Improved Electrostatic Dissipation Properties for Advanced Applications
}

\author{
T. M. Smith ${ }^{1,2}$, G. L. Nelson ${ }^{1}$ \\ ${ }^{1}$ Florida Institute of Technology 150 West University Blvd. Melbourne, FL 32901 \\ ${ }^{2}$ NASA Testbed Technology Branch YA-C2-T Kennedy Space Center, FL 32899
}

\section{Introduction}

Electrostatic dissipative polymers are used for a variety of functions. Typical methods utilized to transform electrically insulating polymers into either charge dissipative or conductive materials involve. incorporating a conductive filler, conductive polymer, oxidizing the surface using plasma, or incorporating surfactants that act as surface wetting agents. Another approach is to synthesize a block copolymer that is expected to result in better electrical properties with minimal impacts to physical, fire, and thermal properties. One such block that can be added into the main chain of polymers is a diol terminated ferrocene oligomer, which is expected to impart electrostatic dissipative properties into the host polymer while concurrently improving the overall fire properties. Previous work with polyurethanes incorporating a ferrocene oligomer into the main chain resulted in much improved fire retardancy. ${ }^{1}$ In dealing with electrostatic dissipative materials the important questions are: how easily does the material charge and how quickly can the charge move to ground. One normally describes the materials conductivity, but conductivity only measures the fastest path for an electron not the slowest path. The slowest path is the one of interest, since it is left on the surface and thus can cause discharges. In order to assess ease of charging and decay times corona charge dissipation measurements can accurately assess these properties by introducing a charge on the surface of the material then measuring the surface voltage and the amount of charge deposited. The charge decay curve then will give an indication of a materials electrostatic dissipation properties. Normally, triboelectric testing can be performed, but results vary. Corona charge dissipation results are more repeatable.

\section{Materials and Methods}

The ferrocene oligomer (FcOlig) shown in Figure 1 was synthesized by first acylating ferrocene via a FriedelsCraft reaction followed by an oxidation reaction to produce 1,1 '-ferrocenedicarboxylic acid. The acid was then transformed into the acid chloride using oxalyl chloride. ${ }^{2}$ A condensation reaction of the acid chloride with 1,6-hexanediol resulted in the diol terminated ferrocene oligomer shown in Figure $1 .^{13-5}$ Polyurethane materials were synthesized using Rubinate(B) 9272 from Huntsman and Minwax $®$ Fast Drying semi-gloss

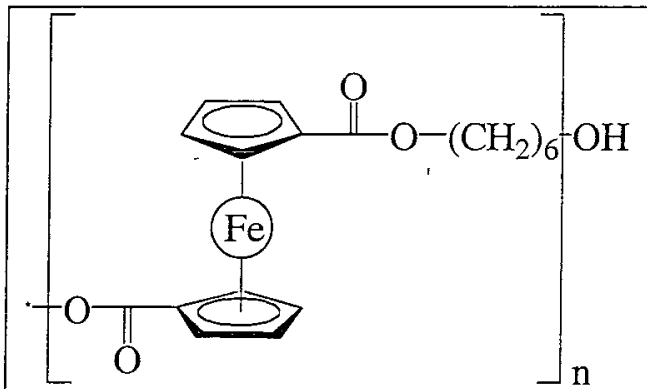

Figure 1. Diol terminated ferrocene oligomer synthesized to form block copolymers with polyurethanes and polyimides.

polyurethane all without further purification. Baytec(8ME080 was used in a previous study. ${ }^{1,5}$ Rubinate $B 9272$ was chosen because it was readily available and it is similar to Baytec®ME080.

Polyurethane materials were cast on to a clean, dry sheet of glass and allowed to cure. Rubinate $(9272$ materials moisture cure and consequently are reactive with amines and diols. Minwax ${ }^{\circledR}$ polyurethanes cure through a catalyzed reaction with oxygen and thus are not reactive with diols and amines. Rubinate ${ }^{\circledR}$ materials all cured within 48 hours at relative humidity levels between 50-60\%. Minwax $\left({ }^{\circledR}\right.$ materials were cured within 24 hours. Rubinate $(\mathbb{B}$ materials synthesized were $1.5 \%$ and $3.5 \%$ by weight ferrocene oligomer allowed to react into the main chain and $5 \%$ and $10 \%$ ferrocene as an additive. A Minwax film with $4 \%$ by weight ferrocene oligomer was synthesized. Unmodified Rubinate ${ }^{\circledR}$ films were white and unmodified Minwax films were clear. Films with ferrocene oligomer added were reddish-brown and films with ferrocene as an additive were yellow.

Polyamic acid was synthesized by dissolving $3,3^{\prime}$ oxydianiline (ODA) into chilled $\left(-10^{\circ} \mathrm{C}\right)$, dry, degassed (nitrogen purge for 15 minutes) $n$-methyl-2-pyrrolidone (NMP) followed by slow addition of an equimolar amount of 3,3',4,4'-biphenyltetracarboxylic dianhydride (BPDA). The solution was stirred for one hour chilled then stirred for two to three hours at room temperature always under a dry nitrogen atmosphere. The solution then was cast onto a clean glass sheet and thermally imidized to form the corresponding polyimide. ${ }^{6,7}$ The ferrocene containing polyimides were made in a similar fashion. The polyamic acid precursor was synthesized by dissolving an appropriate amount of the ferrocene oligomer (FcOlig) into chilled, dry, degassed NMP. An 
appropriate amount of ODA was then dissolved in a separate round bottom flask containing chilled, dry, degassed NMP. An amount of BPDA equaling the sum of the number of moles of ODA and FcOlig was then slowly added to the ODA solution. Five minutes later the FcOlig solution was slowly added to the BPDAODA solution always under a dry nitrogen atmosphere. The solution was allowed to stir for one hour chilled then two to three hours at room temperature. The resulting ferrocene containing polyamic acid solution was cast onto a clean glass sheet then thermally cyclized. Polymethylmethacrylate (PMMA) films were made by dissolving PMMA in toluene and casting onto clean, dry glass sheet.

PMMA films with ferrocene oligomer included as an additve were fabricated by dissolving FcOlig into toluene, then adding the FcOlig solution to a stirring solution of PMMA and then cast onto a clean, dry glass sheet. A PMMA control film and a $9.4 \%$ by weight FcOlig PMMA film were fabricated.

Surface and volume resistance data were collected using a calibrated Pro Stat PRS-801 Resistance System with a Pro Stat PRF-911 Concentric Ring Electrode. All specimens were equilibrated for at least 24 hours at $50 \%$ relative humidity at ambient temperature.

Corona charge dissipation data were collected using a JCI 155 v5 Charge Decay Test Unit in conjunction with a JCI 176 Charge Measuring Sample Support unit from John Chubb Instrumentation. The corona voltage was $10 \mathrm{kV}$ for $20 \mu$ s set to a negative polarity. The ground configuration was set to allow the charge to flow both across the surface and through the bulk material. At least three different locations were tested per sample with at least one location being on the back to ensure the measurement were truly representative of the material. All specimens were de-ionized before each test to ensure the surface potential was zero volts. Samples were equilibrated for at least 24 hours in a $50 \%$ relative humidity environment at ambient temperatures. The combination of using both JCI test units allowed the measurement of capacitance loading and decay time.

FTIR-ATR data were collected on a Shimadzu FTIR8400 S spectrophotometer equipped with a Pike horizontal ATR attachment with a diamond press. The ATR attachment allows for a single bounce at $45^{\circ}$ and the number of scans was set to 20 at wavenumber resolution of $4 \mathrm{~cm}^{-1}$.

XPS data were obtained on a Kratos XSAM 800 Spectrometer using a $\mathrm{MgK} \alpha(\mathrm{hv}=1253.6 \mathrm{eV}) \mathrm{x}$-ray source. Samples were etched using a $3 \mathrm{kV}$ argon ion beam, rastered over an area of $2 \times 4 \mathrm{~mm}$. The lens was apertured down to a $1 \mathrm{~mm}$ spot size for analysis after etching to ensure the data collected was from well within the etch site. The etch depth was calibrated relative to a $\mathrm{Ta}_{2} \mathrm{O}_{5}$ standard of known thickness.
Surface and volume resistance data for fabricated polyurethanes, PMMA, and polyimides are listed in Table 1. Unmodified moisture cured Rubinate $§ 9272$ polymer films exhibited insulating characteristics. Rubinate ${ }^{\circledR}$ polyurethanes, which contained ferrocene as an additive, were also measured to have similar resistance as the unmodified Rubinate $B$. Only when the ferrocene oligomer was allowed to bond into the chain did the surface and volume resistance measurement decrease significantly. Aged polyurethane (Baytec ${ }^{\circledR}$ ME080 5\% FcOlig) exhibited similar electronic properties as the newly prepared Rubinate $®$ material. There was no significant decrease of resistance for

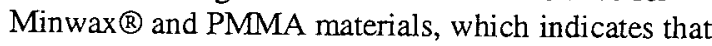
ferrocene is required to be in the chain. PMMA and Minwax ${ }^{\circledR}$ materials exhibited decreased surface conductivity of $17 \%$ and $29 \%$, in comparison to a nearly $2700 \%$ decrease for Rubinate ( with $3.5 \%$ ferrocene oligomer reacted into the chain. The polyimides with the ferrocene oligomer in the chain showed only a modest decrease in surface and volume resistance, which seems to contradict what was observed in the Rubinate $(\mathbb{B}$ materials.

Table 1. Surface and volume resistance for polyurethanes, PMMA, and polyimides. Reported data is an average of at least 5 measurements over the entire film including front and back.

\begin{tabular}{|c|c|c|}
\hline Material & $\begin{array}{c}\text { surface } \\
\text { resistance } \\
\text { (T } \Omega / \text { sq. })\end{array}$ & $\begin{array}{l}\text { volume } \\
\text { resistance } \\
(\mathrm{T} \Omega \bullet \mathrm{cm})\end{array}$ \\
\hline Rubinate@9272 control & $1.44 \pm .26$ & $1.64 \pm .43$ \\
\hline Rubinate $® 1.5 \%$ FcOlig & $0.49 \pm 0.46$ & $0.82 \pm 0.04$ \\
\hline Rubinateß $3.5 \%$ FcOlig & $0.054 \pm 0.007$ & $0.14 \pm 0.01$ \\
\hline Rubinate@ $10 \%$ ferrocene & $1.24 \pm 0.30$ & $1.96 \pm 0.38$ \\
\hline Rubinate $(5 \%$ ferrocene & $1.25 \pm 0.25$ & $1.64 \pm 0.21$ \\
\hline Baytec(RME080 5\%FcOlig & $0.41 \pm 0.01$ & $0.16 \pm 0.05$ \\
\hline Minwax® control & $8.23 \pm 2.49$ & --- \\
\hline Minwax $(4 \%$ FcOlig & $5.81 \pm 0.84$ & --- \\
\hline PMMA control & $241 \pm 83$ & $1951 \pm 352$ \\
\hline PMMA 9.4\% FcOlig & $201 \pm 76$ & $1932 \pm 297$ \\
\hline Upilex® S BPDA-ODA PI & $581 \pm 85$ & 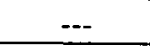 \\
\hline BPDA-ODA PI control & $357 \pm 28$ & $865 \pm 311$ \\
\hline BPDA-ODA $1.5 \%$ FcOligPI & $311 \pm 104$ & $936 \pm 174$ \\
\hline BPDA-ODA $6 \%$ FcOlig PI & $302 \pm 52$ & $491 \pm 95$ \\
\hline
\end{tabular}

Corona charge dissipation confirmed the resistance data. The surface potential of polyurethane materials that have ferrocene oligomer reacted into the chain exhibited a much lower initial surface potential, faster charge decay times, and significantly improved capacitance loading. Capacitance loading is as important as charge decay, because capacitance loading depends on charge deposited on the surface and the peak surface potential relative to a thin good dielectric material such as polyethylene. ${ }^{8}$ High capacitance loading leads to lower surface potentials on a material, thus resulting in less chance of discharge. Recommendations from John Chubb are that charge decay times be less than $200 \mathrm{~ms}$

\section{Results and Discussion}


and that capacitance loading should be 100 or greater for materials to be considered charge dissipative. ${ }^{9}$ All polyurethane materials that had ferrocene oligomer reacted into the chain had charge decay times less than $200 \mathrm{~ms}$ and the Rubinate $囚 3.5 \% \mathrm{FcOlig}$ material had an average capacitance loading value of 154 .

Table 2. Corona charge dissination data collected for Rubinate $®$ and Baytec ${ }^{\circledR}$ polyurethanes (fabricated in 1999). Reported data is an average of at least $\mathbf{3}$ measurements over the entire film including front and back.

\begin{tabular}{|c|c|c|c|}
\hline Material & $\begin{array}{c}\text { capacitance } \\
\text { loading }\end{array}$ & $\begin{array}{c}\text { decay } \\
\text { time } 1 / \mathrm{e} \\
(\mathrm{ms})\end{array}$ & $\begin{array}{c}\text { initial } \\
\text { voltage } \\
\text { (V) }\end{array}$ \\
\hline $\begin{array}{l}\text { Rubinate(B) } 9272 \\
\text { control }\end{array}$ & $1.19 \pm 0.11$ & $935 \pm 55$ & $1605 \pm 65$ \\
\hline $\begin{array}{l}\text { Rubinate }(10 \% \\
\text { ferrocene }\end{array}$ & $1.11 \pm 0.01$ & $2103 \pm 51$ & $1706 \pm 16$ \\
\hline $\begin{array}{l}\text { Rubinateß } 5 \% \\
\text { ferrocene }\end{array}$ & $1.20 \pm 0.01$ & $563 \pm 32$ & $1681 \pm 17$ \\
\hline $\begin{array}{l}\text { Rubinate® } 1.5 \% \\
\text { FcOlig }\end{array}$ & $2.71 \pm 0.21$ & $81 \pm 8$ & $1098 \pm 37$ \\
\hline $\begin{array}{l}\text { Rubinate }(3) 3 \% \\
\text { FcOlig }\end{array}$ & $154.4 \pm 26$ & $131 \pm 26$ & $136 \pm 6$ \\
\hline $\begin{array}{l}\text { Baytec BME080 } \\
5 \% \text { FcOlig }\end{array}$ & $3.17 \pm 1.46$ & $174 \pm 65$ & $1214 \pm 193$ \\
\hline
\end{tabular}

Figure 2 illustrates typical corona charge decay curves for polyurethane materials tested. It is clear that the Rubinate $\otimes$ control and Rubinate $\otimes$ materials with ferrocene as an additive charge much higher and decay much slower than materials that have ferrocene oligomer in the chain.

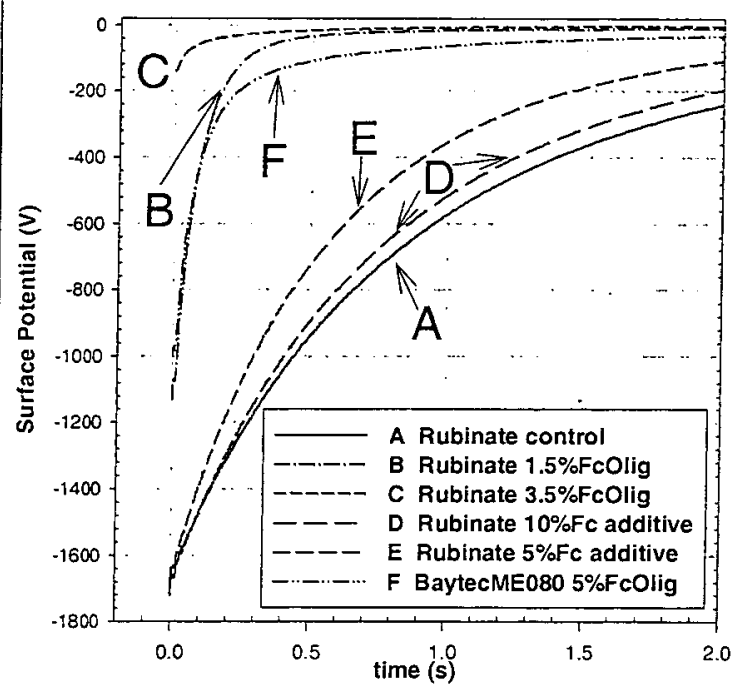

Figure 2. Typical corona charge decay curves for polyurethane materials.

In contrast, all polyimide materials charged to about $1800 \mathrm{~V}$ and stayed charged for minutes. The polyimide materials are such good insulators they would have likely stayed charged for weeks. ${ }^{10}$ What is so different between the polyimide and polyurethane materials?
X-Ray Photoelectron Spectroscopy (XPS) and Fourier Transform Infrared Attenuated Total Reflectance (FTIR-ATR) both confirm that in Rubinate $($ materials the ferrocene oligomer is on the surface and through the sub-surface. In the polyimides ferrocene was not detected on the surface or after etching $1000 \AA$, and even after scraping the film with a sharp scalpel. Iron was finally detected in the $6 \%$ by weight FcOlig BPDAODA sample via Energy Dispersive $\mathrm{X}$-ray Spectroscopy (EDS). In low Z materials like polymers a $20 \mathrm{keV}$ electron beam should be able to probe fairly deep. A Monte Carlo simulation using Electron Flight Simulator program and choosing carbon as the medium indeed showed that a $20 \mathrm{keV}$ electron beam would probe down between 5-6 $\mu \mathrm{m}$, thus indicating that ferrocene oligomer was partitioned in the bulk of the polyimide film. This confirmed that iron was present in the polyimide, but not on nor near the surface.

\section{Conclusion}

Insulating materials were made charge dissipative by introducing small quantities of a ferrocene oligomer into the chain of a host polymer. All indications suggest that the ferrocene oligomer is required to be reacted into the chain, otherwise similar electronic changes would have been measured in PMMA and Minwax® materials. Similarly, the ferrocene oligomer should be positioned on or near the surface in order to achieve improvements in conductivity and charge dissipation. Incorporating a small amount of ferrocene oligomer into the chain of a host matrix can lead to improved electrostatic properties. Materials prepared by this approach can clearly be considered; "Charge Dissipative".

\section{References}

[1] Najafi-Mohajeri, N.; Nelson, G. L.; Benrashid, R. Journal of Applied Polymer Science 2000, 76, 1847 1856.

[2] Knobloch, F. W.; Rauscher, W. H. J. Poly. Sci. $1961,54,651-656$.

[3] Valot, H. C.R. Acad. Sc. Paris Series C. 1966, 262, 403-405.

[4] Valot, H. Bull. Soc. Chim. Fr. 1969, 6.

[5] Najafi-Mohajeri, N., Ph.D. Dissertation, 1999.

Florida Institute of Technology, Melboume, p. 160.

[6] Igarashi, K.; Yamaguchi, K., Process for Producing Polyimide Precursor. US4499252, March 28, 1984, 1985.

[7] Inoue, H.; Sasaki, Y.; Ogawa, T. Journal of Applied Polymer Science 1996, 60, 123-131.

[8] Chubb, J. N. Journal of Electrostatics 2002, 54, 233-241.

[9] Chubb, J. N. IEEE Trans Ind Appl, Phoenix, Arizona, 1999, pp 1515-1522.

[10] Frederickson, A. R.; Benson, C. E.; Bockman, J. F. Nuclear Instruments \& Methods in Physics Research, Section B: Beam Interactions with Materials and Atoms 2003, 208, 454-460. 